\title{
Central catecholamine metabolism in vivo and the cognitive and motor deficits in Parkinson's disease
}

\author{
J JOHN MANN, MICHAEL STANLEY, ${ }^{*}$ RICHARD D KAPLAN, JOHN SWEENEY, \\ ANDREAS NEOPHYTIDES
}

From the Department of Psychiatry, Payne Whitney Clinic, Cornell University Medical College, New York, USA

SUMMARY Cerebrospinal fluid levels of homovanillic acid (HVA) in unmedicated patients with Parkinson's disease were $45 \%$ of levels in control subjects. Levels of 3methoxy-4-hydroxyphenylglycol (MHPG) and platelet monoamine oxidase activity (MAO) did not differ. Within the Parkinson's disease group platelet MAO B activity correlated with HVA (an MAO B substrate) but not MHPG (an MAO A substrate). A mild global dementia was found that did not correlate with the more severe motor deficit. There was a negative correlation between the motor deficit and HVA levels but not with MHPG. Cognitive functioning correlated positively with platelet MAO, and the ratio of HVA to MHPG levels and negatively with MHPG alone. It is postulated that dopaminergic and noradrenergic activity or the functional balance between these systems may contribute to the observed cognitive dysfunction.

Studies of necropsy brain tissue and cerebrospinal fluid have demonstrated a relationship between the motor deficit in Parkinson's disease and levels of dopamine (DA) and homovanillic acid (HVA). ${ }^{1-8}$ In contrast CSF levels of 5-hydroxyindolacetic acid (5-HIAA) and 3-methoxy-4-hydroxyphenylglycol (MHPG) have not been found to be altered in Parkinson's disease. ${ }^{4-8}$ However, levels of brain noreprinephrine (NE) and MHPG are reported as low in certain brain regions postmortem. ${ }^{\circ}$ Other neurochemical findings reported in Parkinson's disease include: decreased activity of dopa decarboxylase in the striatum, ${ }^{10}$ alterations in striatal neuroleptic binding ${ }^{11}$ and cortical serotonin binding $;{ }^{12}$ and reduced methionine-enkephalin levels in the substantia nigra and the ventral tegmental area. ${ }^{13}$

In contrast to the detailed studies of the relationship between the dopaminergic system and the

\footnotetext{
*Present address: Departments of Psychiatry and Pharmacology, Wayne State University Medical School and the Lafayette Clinic, Detroit, Michigan, 48207, USA.
}

Address for reprint requests: Dr JJ Mann, Dept of Psychiatry, Payne Whitney Clinic, Cornell University Medical College, 525 East 68th St, New York, NY10021, USA.

Received 3 August 1982 and in final revised form 18 April 1983. Accepted 7 May 1983. motor deficit, there are no published studies examining the relationship between central catecholamine metabolism and the cognitive deficit in Parkinson's disease. Yet there are reports that levodopa therapy can improve both cognitive function and motor function in Parkinson's disease. ${ }^{14-16}$ A positive correlation has also been reported between the degree of dementia and bradykinesia ${ }^{17}$ which in turn has been reported elsewhere to correlate with the deficit in CSF and brain HVA levels. Furthermore there is evidence suggesting it is actually the relative balance of dopaminergic and noradrenergic activity that is important for optimal cognitive function. ${ }^{18} \mathrm{We}$ therefore thought it of interest to examine the potential relationship of motor and cognitive performance in Parkinson's disease with CSF levels of both HVA and MHPG (the major metabolite of norepinephrine in the CNS) and platelet monoamine oxidase activity (a peripheral source of MAO $B$, the major intraneuronal degradative enzyme for DA in human striatum). ${ }^{19}$

\section{Method and subjects}

The 17 male patients with Parkinson's disease who entered this study were either drug-free and being evaluated for treatment for the first time or had undergone drug washout for at least 2 weeks preparatory to evaluation of new antiparkinsonian agents. Written informed consent was 
Table 1 Comparison of unmedicated Parkinson's disease patients and normal controls with respect to age, central catecholamine metabolites, platelet MAO and cognitive deficit.

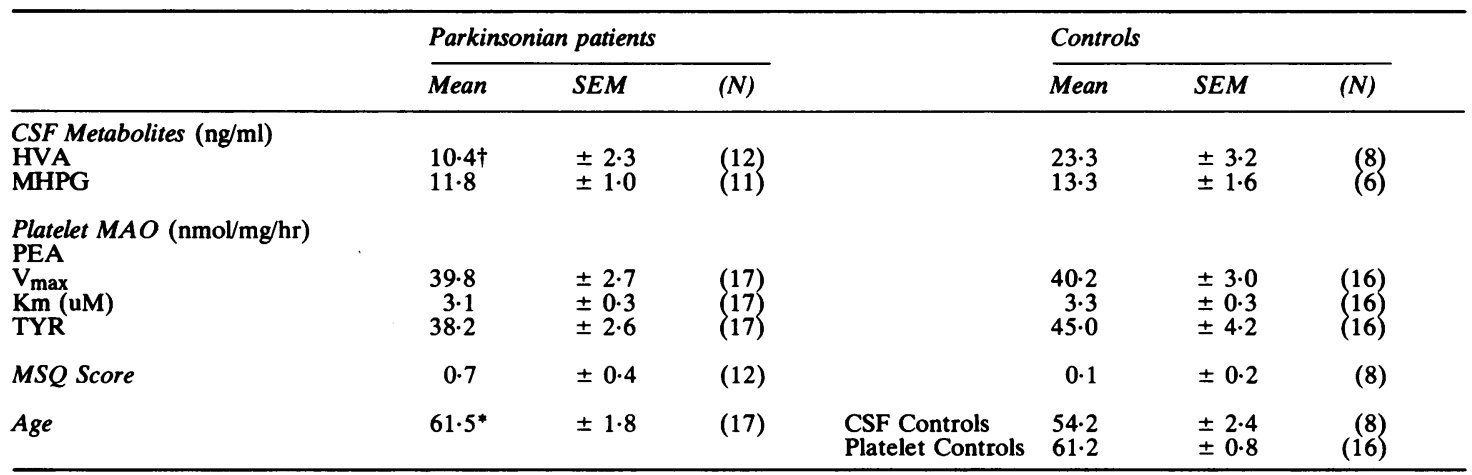

${ }^{*} \mathrm{p}<0.05 . \dagger \mathrm{p}<0.012$-tail $\mathrm{t}$ test contrast with controls.

obtained from all patients. The motor deficit was measured using the New York University Scale ${ }^{20}$ and the scale of Hoehn \& Yahr. ${ }^{21}$ The cognitive deficit was measured using the Mental Status Questionaire (MSQ) ${ }^{22}$ and the Guild Memory Scale. ${ }^{23}$ The MSQ is a test of basic knowledge of personal and general information and orientation. The Guild Memory Scale includes the following tests: (1) delayed recall of visual information (designs), (2) immediate and delayed recall of meaningfully related (paragraphs) and randomly paired (paired associates) verbal information, and (3) attention (digit span).

Levels of HVA and MHPG were measured in CSF collected by lumbar puncture performed at 0900 hours in inpatients after 24 hours on a low amine diet (adapted from that prescribed for patients on monoamine oxidase inhibitors). The first $15 \mathrm{ml}$ of CSF was discarded and the next $8 \mathrm{ml}$ used for the catecholamine assays. Platelet MAO samples were taken within 24 hours of the lumbar puncture. HVA and MHPG were measured using a gas chromatographic technique with electron capture..$^{24}$ Platelet MAO enzyme kinetics were measured using ${ }^{14} \mathrm{C}$ phenyethylamine and enzyme activity using ${ }^{14} \mathrm{C}$-tyramine according to our previously published methods. ${ }^{26}$ All assays were done in duplicate on coded samples by technicians blind to the clinical data. Results were compared to a

Table 2 Guild Memory Scale Scores in 12 unmedicated Parkinson's disease patients and controls (mean $\pm S D$ )

\begin{tabular}{|c|c|c|}
\hline $\begin{array}{l}\text { Guild Memory } \\
\text { Scale subscores }\end{array}$ & $\begin{array}{l}\text { Parkinson's disease } \\
\text { group scores ( } \% \\
\text { normal group mean) }\end{array}$ & $\begin{array}{l}\text { Age-matched and } \\
\text { verbal } I Q \text {-matched } \\
\text { normal control scores } \ddagger\end{array}$ \\
\hline $\begin{array}{l}\text { Paragraphs } \\
\text { Immediate } \\
\text { Delayed } \\
\text { Paired Associates }\end{array}$ & $\begin{array}{l}4.75 \dagger \pm 2.47(68 \%) \\
5.58 \dagger \pm 3.72(66 \%)\end{array}$ & $\begin{array}{l}7 \cdot 0 \pm 2 \cdot 0 \\
8 \cdot 5 \pm 2 \cdot 0\end{array}$ \\
\hline $\begin{array}{l}\text { Immediate } \\
\text { Delayed } \\
\text { Digit Span } \\
\text { Designs }\end{array}$ & $\begin{array}{l}: 2 \cdot 33 \dagger \pm 1 \cdot 23(58 \%) \\
: 2 \cdot 58 \dagger \pm 1.44(52 \%) \\
8 \cdot 0^{*} \pm 3.28(20 \%) \\
: 2 \cdot 58 \dagger \pm 1.88(52 \%)\end{array}$ & $\begin{aligned} 4 \cdot 0 & \pm 2 \cdot 0 \\
5 \cdot 0 & \pm 2 \cdot 0 \\
10 \cdot 0 & \pm 3 \cdot 0 \\
5 \cdot 0 & \pm 3 \cdot 0\end{aligned}$ \\
\hline
\end{tabular}

\$Normative data obtained from Gilbert and Levee ${ }^{23}(\mathrm{n}=133)$ ${ }^{*} \mathrm{p}<0.05+\mathrm{p}<0.012$-tailed $\mathrm{t}$ test contrast with control values group of age-matched drug-free normal male controls who had platelet MAO measured and a second group of male inpatient controls who were being investigated for low back pain and headache, where no neurological cause was found and in whom CSF was collected and MHPG and HVA measured in the same manner as for the Parkinsonion group.

\section{Results}

The 17 Parkinson patients studied had a duration of illness of $13 \cdot 5 \pm 0 \cdot 4$ (SEM) years. The neurochemical findings are summarised in table 1 . The mean concentration of HVA in the CSF of the Parkinson's disease group was $45 \%$ that of the control group $(p<0.01)$. There were no apparent differences in the level of CSF MHPG. Because of the possibility that platelet MAO activity may increase in older patients, the platelet MAO control group was agematched with the Parkinsonian patients. There were no differences in platelet MAO $\mathrm{V}_{\max }$ or $\mathrm{K}_{\mathrm{m}}$ between the disease group and the control group.

The patients with Parkinson's disease had a moderately severe motor deficit with mean scores of 3.3 \pm 1.0 on the scale of Hoehn and Yahr and $852 \pm$ 105 on the New York University Scale. Cognitive function was also impaired. The group as a whole scored below the mean for age and verbal IQmatched controls on all six subscales of the Guild Memory Scale (see table 2). The degree of deficit was actually very similar across all subscales as can be seen by the percentage differences in the mean scores shown in table 2 . These findings could not be attributed to attention deficits or motor function since the digit span score showed the least effect and the designs score, where some degree of motor function is required, was comparable to scores on other subscales of the Guild Memory Scale. 
Table 3 Relationship in Parkinson's disease of CSF Catecholamine metabolites and platelet monoamine oxidase kinetics: partial correlation matrix controlling for age

\begin{tabular}{lccc}
\hline CSF metabolites & \multicolumn{2}{c}{ Platelet MAO kinetics } & Tyramine activity \\
& $V_{\max }$ & Km & \\
\hline HVA & $0.55^{*}$ & 0.04 & $0.47 \dagger$ \\
MHPG & -0.25 & 0.06 & -0.10 \\
\hline
\end{tabular}

p $p<0.05$

$+\mathrm{p}<0 \cdot 10$

The motor deficit as measured by the NYU Scale did not correlate with any of the measures of cognitive function. A negative partial correlation controlling for age was found between the motor deficit score on the NYU scale and CSF HVA levels $(r=$ $-0.70, p<0.01)$. No correlation was found with MHPG.

Within the group of neurochemical measures, platelet MAO activity (a peripheral source of MAO B) showed a partial correlation controlling for age with CSF levels of HVA (an MAO B substrate) but not with MHPG (an MAO A substrate) when controlled for age (see table 3). Platelet MAO activity and CSF HVA showed no positive correlation with age in patients with Parkinson's disease, in contrast to positive findings previously reported in both brain and platelet tissue in normal subjects. ${ }^{29}$

The relationships between the measures of cognitive deficit on the Guild Memory Scale and catecholamine metabolites are shown in table 4 . Platelet MAO activity showed a positive correlation with the MSQ and 4/6 subscales on the Guild Memory Scale and a trend towards a positive correlation with a fifth subscale $(p<0 \cdot 10)$. Thus higher platelet MAO B activity was associated with better cognitive performance. No significant correlation was seen between HVA and any cognitive measure although the paired associates approached significance $(p<$ $0 \cdot 10)$. A negative correlation was found between CSF MHPG levels and scores on the digit span sub- scale as well as trend towards a negative correlation $(\mathrm{p}<0 \cdot 1)$ with the paragraphs and paired associates subscales scores. All correlation coefficients with MHPG were negative, regardless of significance. Platelet MAO $\mathrm{V}_{\max }$ and MHPG collectively explained $14-39 \%$ of the variance in the cognitive subscales of the Guild Memory Scale (see table 4). Similarly the ratio of HVA to MHPG explained a significant part of the variance for both immediate and delayed recall of the paired associates and the digit span subscales.

Within the cognitive measures carried out on the Parkinson's disease group a strong correlation was found between scores on subscales on the Guild Memory Scale $(p<0.01)$ supporting the suggestion derived from the relatively equal degree of deficit seen in all the subscales of the Guild Memory Scale that Parkinson's disease did not selectively impair any of the specific cognitive processes measured by the Guild Memory Scale.

\section{Discussion}

Our finding of reduced CSF concentrations of HVA in the Parkinson's disease group compared to controls and that the level of HVA correlated significantly with the degree of motor deficit after controlling for age is in agreement with findings in both brain ${ }^{14}$ and CSF. ${ }^{17}$ We found no differences in CSF MHPG levels between the Parkinson's disease group and controls again confirming a previous report, ${ }^{8}$ although there is one postmortem study that reported reduced concentrations of MHPG and NE in Parkinson's disease..$^{9}$ As spinal sources of MHPG may obscure a central deficit when measuring CSF MHPG by lumbar puncture, our findings cannot exclude a central deficit of NE.

We also found no differences in platelet MAO enzyme kinetics between the diseased and the control groups which is consistent with the one published study of platelet MAO activity in Parkinson's

Table 4 Relationship of cognitive deficit in Parkinson's disease to CSF catecholamine metabolites and platelet MAO activity: partial correlation matrix controlling for age.

\begin{tabular}{|c|c|c|c|c|c|c|c|c|}
\hline \multirow{2}{*}{$\begin{array}{l}\text { Guild Memory } \\
\text { Scale Subtests }\end{array}$} & & \multirow[t]{2}{*}{$H V A$} & \multirow[t]{2}{*}{$M H P G$} & \multirow{2}{*}{ Ratio $\frac{H V A}{M H P G}$} & \multirow{2}{*}{\multicolumn{2}{|c|}{$\begin{array}{l}\text { Platelet } \mathrm{MAO} \text { kinetics } \\
V_{\max } \mathrm{Km}\end{array}$}} & \multirow{2}{*}{$\begin{array}{l}\text { Tyramine } \\
\text { activity }\end{array}$} & \multirow[t]{2}{*}{$V_{\max }$ and $M H P G \S$} \\
\hline & & & & & & & & \\
\hline $\begin{array}{l}\text { Paragraphs } \\
\text { Paragraph 2‡ } \\
\text { Paired Associates } \\
\text { Paired Associates } \\
\text { Digit Span } \\
\text { Designs }\end{array}$ & 2 & $\begin{array}{c}-0.30 \\
0.21 \\
0.49 \dagger \\
0.31 \\
0.42 \\
-0.40\end{array}$ & $\begin{array}{l}-0.53 \dagger \\
-0.23 \\
-0.33 \\
-0.48 \dagger \\
-0.74^{*} \\
-0.26\end{array}$ & $\begin{array}{l}0.03 \\
0.36 \\
0.61^{*} \\
0.46^{*} \\
0.61^{*} \\
0.04\end{array}$ & $\begin{array}{r}-0.51^{*} \\
0.46 \dagger \\
0.60^{*} \\
0.76^{*} \\
0.62^{*} \\
-0.02\end{array}$ & $\begin{array}{c}0.07 \\
0.11 \\
0.24 \\
0.38 \\
0.17 \\
-0.75^{*}\end{array}$ & $\begin{array}{l}0.33 \\
0.28 \\
0.47 t \\
0.60^{*} \\
0.37 \\
0.36\end{array}$ & $\begin{array}{l}0.59^{*} \\
0.52 \dagger \\
0.60^{*} \\
0.62^{*} \\
0.53^{*} \\
0.37\end{array}$ \\
\hline
\end{tabular}

*p $<0.05$

$+\mathrm{p}<0.10$

$\ddagger$ Delayed recall of paragraph or paired associates

\$Multiple linear regression using $V_{\max }$ and MHPG as independent variables 
disease in untreated and levodopa-treated patients. ${ }^{27}$ This paper reported no significant differences in platelet MAO activity between controls and the untreated Parkinson's disease group, but because the ratio of MAO activity using the substrates tyramine and m-iodobenzylamine was significantly lower in the Parkinson's disease group, an alteration in the enzyme was postulated. However they did not do enzyme kinetic studies. In our study we did measured MAO enzyme kinetics and found no differences in the Michaelis constant, $\mathrm{Km}$, which suggests that platelet MAO is not altered in Parkinson's disease.

The relationship of platelet MAO to central catecholamine metabolism has only received limited attention. DA is an MAO B substrate in human striatum $^{19}$ and platelet MAO is almost entirely type $B$. We would expect that since MAO is the major intraneuronal degradative enzyme of amines and that genetic factors account for about $70 \%$ of the variance in platelet MAO activity, ${ }^{28}$ that it may reflect central MAO B activity in contrast to MAO $A$ activity. In fact, consistent with this suggestion, there was a positive correlation between platelet MAO activity and HVA levels but not MHPG levels. Clearly this finding requires further investigation in both diseased and normal control subjects to evaluate to what degree platelet MAO activity can reflect central DA metabolism. Postmortem studies have shown that brain MAO activity can correlate postively with levels of 5-HIAA ${ }^{29}$ but detailed studies of correlations between central and peripheral MAO A and B activity and preferred substrates are lacking in human subjects apart from one study that confirmed out findings in normal controls. ${ }^{30}$

Previous reports in other older patient populations have indicated a positive correlation between age and both platelet MAO B activity and CSF levels of HVA. ${ }^{31}{ }^{32}$ In contrast to these findings in normal subjects, we found no statistically significant correlation between age and either CSF HVA ( $r=$ $0.39 \mathrm{p}>0.10)$ and platelet MAO $(r=0.05 \mathrm{p}>$ $0 \cdot 10)$ in Parkinson's disease. These differences could be explained by the effect of the disease upon CSF HVA and the relatively narrow spread of ages in this group which could conceal an age-related rise in platelet MAO activity.

Cognitive testing in our study suggested a mild global deficit that contrasted with the severity of the motor deficit. While animal data suggests certain lesions of the basal ganglia can produce profound deficits in "cognitive function", human diseases of the basal ganglia produce principally motor lesions. ${ }^{33}$ Our finding of a mild global cognitive impairment contrasts with some reports in the litera- ture of a more focal cognitive defect. ${ }^{14} 1534$ Some of these reports may have failed to allow for motor deficits and since certain visual/spatial tasks may also measure motor functioning, this methodological point may explain why greater deficits have been reported in this area of cognitive function..$^{14} 15$ The differences in both the rate of progression and the underlying neurochemical basis of the cognitive and motor deficits may explain ours and others' failure to find a significant correlation in severity between these two components of Parkinson's disease.

The pattern of correlation after controlling for age between the cognitive test subscores on the Guild Memory Scale and the levels of HVA and MHPG in the CSF was intriguing. We found a statistically significant negative correlation between CSF MHPG and scores on the digit span and a trend for a similar finding $(p<0 \cdot 10)$ with the paragraphs and paired associates subscales. Norepinephrine has been shown in animal studies ${ }^{35}$ to act as a neuromodulator in facilitating memory functions and our findings in Parkinson's disease suggest a role in cognitive function for $\mathrm{NE}$ in man.

We could not rule out an effect for DA in cognitive function in Parkinson's disease because platelet MAO activity and HVA levels showed similar relationships with cognitive deficit that reached statistical significance where higher MAO B activity was associated with higher scores on the MSQ and 5/6 Guild Memory Scale subscores. Consistent with the relationship of MAO B with cognitive function, HVA levels tended to show positive correlations with cognitive function. The ratio of HVA to MHPG correlated significantly with $3 / 6$ Guild subscales and similarly the combination of the two independent variables, platelet MAO $V_{\max }$ and MHPG contributed significantly to the variance on $4 / 6$ subscales. While these findings suggest a relationship between NE and/or DA and cognitive function, an alternative suggestion is that an imbalance created by DA underfunction and relatively normal NE activity may contribute to the abnormality in cognitive functioning in Parkinson's disease. ${ }^{18}$ Clearly a larger series of patients must be studied to see if these data can be confirmed and to investigate these suggested causal relationships.

Our findings suggest that while the motor deficit of Parkinson's disease is related to a deficiency of dopamine in nigrostriatal neurons, certain aspects of cognitive function or dysfunction appear related to both NE and DA or perhaps the relative imbalance that develops between the dopaminergic system and noradrenergic function. These observations emphasise the need for further study of the functional interrelationship between these aminergic systems and cognitive and motor function in order to permit a 
better understanding of the neurochemical basis of both the motor and cognitive deficits in Parkinson's disease.

This work was partly supported by an Andrew W Mellon Teacher-Scientist Award to Dr John Mann. Excellent technical assistance was provided by Ms Joan Kuster, Francesca Iohan and $\mathrm{Mr}$ Allaix Philogene. Assistance with data compilation was provided by Ms Maria Collora.

\section{References}

${ }^{1}$ Bernheimer H, Birkmayer W, Hornykiewicz O, Jellinger $\mathrm{K}$, Seitelberger F. Brain dopamine and the syndromes of Parkinson and Huntington. $J$ Neurol Sci 1973;20:415-55.

2 Johansson B, Roos B-E. 5-hydroxyindoleacetic and homovanillic acid levels in the cerebrospinal fluid of healty volunteers and patients with Parkinson's syndrome. Life Sci 1967;6:1449-54.

${ }^{3}$ Van Woert MH, Bowers MB. The effect of L-dopa on monoamine metabolites in Parkinson's disease. Experientia (Basel) 1970;26:161-3.

${ }^{4}$ Papeschi R, Molina-Negro P, Sourkes TL, Erba G. Concentration of homovanillic acid in the ventricular fluid of patients with Parkinson's disease and other dyskinesias. Neurology (Minneap) 1970;20:991-5.

${ }^{s}$ Guldberg HC, Turner JW, Hanieh A et al. On the occurrence of homovanillic acid and 5-hydroxyindoleacetic acid in the ventricular CSF of patients suffering from Parkinsonism. Conf Neurol 1967;29:73-7.

' Parkes JD, Marsden CD, Rees JE et al. Parkinson's disease, cereral arteriosclerosis, and senile dementia. $Q J$ Med 1974;169:49-61.

7 Tabaddor K, Wolfson LI and Sharpless NS. Ventricular fluid homovanillic acid and 5-hydroxy-indoleacetic acid concentrations in patients with movement disorders. Neurology (Minneap) 1978;28:1249-53.

${ }^{8}$ Davidson DLW, Yates CM, Mawdsley C, Pullar IA, Wilson $\mathrm{H}$. CSF studies on the relationship between dopamine and 5-hydroxytryptamine in Parkinsonism and other movement disorders. J Neurol Neurosurg Psychiatry 1977;40:1136-41.

${ }^{9}$ Riederer P, Birkmayer W, Seeman D et al. Brain noradrenaline and 3-methoxy-4 hydroxyphenylglycol in Parkinson's syndrome. $J$ Neural Transm 1977;41:241-51.

${ }^{10}$ Lloyd KG, Hornykiewicz O. Parkinson's disease: activity of L-dopa decarboxylase in discrete brain regions. Science 1970;170:1212-3.

"Rinne UK, Lonnberg P and Koskinen V. Dopamine receptors in the Parkinsian Brain. J Neural Transm 1981;51:97-106.

12 Kienzl E, Riederer P, Jellinger K et al. Transitional state of central serotonin receptors in Parkinson's disease. $J$ Neural Transm 1981;51:113-22.

${ }^{13}$ Taquet H, Javoy-Agid F, Cesselin F, Agid Y.
Methionineenkephalin deficiency in brains of patients with Parkinson's disease. Lancet 1981;1:1367-8.

${ }^{14}$ Meier M, Martin W. Intellectual changes associated with levadopa therapy. JAMA 1970;213:465-6.

${ }^{15}$ Loranger A, Goodell $\mathrm{H}$, Lee J and McDowell F. Levadopa treatment of Parkinson's syndrome. Arch Gen Psychiatry 1972;26:163-8.

${ }^{16}$ Donnelly EF, Chases N. Intellectual and memory function in Parkinsonian and Nonparkinsonian patients treated with L-dopa. Dis Ner Sys 1973;34:119-23.

${ }^{17}$ Martilla R, Rinne U. Dementia in Parkinson's disease. Acta Neurol Scand 1976;54;431-41.

${ }^{18}$ Antelman S and Cagguila A. Norepinephrine-dopamine interactions and behavior. Science 1977;195:646-53.

${ }^{19}$ Glover V, Sandler M, Owen F et al. Dopamine is a monoamine axidase B substrate in man. Nature 1977;265:81-1.

${ }^{20}$ Lieberman AN, Dziatelowski M, Kupersmith M et al. The evaluation of Parkinson's disease. In: Calne D, Goldstein M, Lieberman A, Thorner M. eds. Advances in biochemical pharmacology. New York: Raven Press, Vol. 23; 1980:277-86.

${ }^{21}$ Hoehn MM, Yahr MD. Parkinsonism: onset, progression and mortality. Neurology (Minneap) 1967;17:427-42.

${ }^{22}$ Kahn RL, Goldfarb AI, Pollack A, Peck A. Brief objective measures of the determination of mental status in the aged. Am J Psychiat 1960;117:326-8.

${ }^{23}$ Gilbert J, Levee R. Patterns of declining memory. $J$ Gerentology 1977;26:70-5.

${ }^{24}$ Watson E, Wilk S. Assessment of cerebrospinal fluid levels of dopamine metabolites by gas chromatography. Psychopharmacologia (Berl) 1975;42:57-62.

${ }^{25}$ Stanley M, Iohan F. A new gas chromatographic method of CSF. Research Communications in Psychology, Psychiatry and Behavior 1980;5:419-26.

${ }^{26}$ Mann JJ, Kaplan RD, Georgotas A et al. Monoamine oxidase activity and enzyme kinetics in three subpopulations of density-fractionated platelets in chronic paranoid schizophrenics. Psychopharmacology $1981 ; 74 ; 344-8$.

${ }^{27}$ Zeller EA, Boshes B, Arbit J et al. Molecular biology of neurological and psychiatric disorders. 1. Effect of Parkinsonism, age, sex and L-dopa on platelet monoamine oxidase. J Neural Transm 1976;39:63-77.

${ }^{28}$ Nies A, Robinson DS, Harris LS, Lamborn KR. Comparison of monoamine oxidase substrate activities in twins, schizophrenics, depressives and controls. In Usdin E, ed. Neuropsychopharmacology of monoamines and their regulatory enzymes Raven Press, New York, p. 59-70, 1974.

${ }^{29}$ Robinson DS, Sourkes TL, Nies A et al. Monoamine metabolism in human brain. Arch Gen Psychiatry 1977;34:89-92.

${ }^{30}$ Oreland L, Wiberg A, Asberg $M$ et al. Platelet MAO activity and monoamine metabolites in cerebrospinal fluid in depresses and suicidal patients and in healthy controls. Psychiatry Res 1981;4:21-9.

${ }^{31}$ Bowers MB, Gerbode FA. Relationship of monoamine metabolites in human cerebrospinal fluid to age. Nature 1968;219:1256-7.

${ }^{32}$ Mann JJ, Stanley M, Neophytides A, de Leon MJ, Ferris 
SH, Gershon S. Central amine metabolism in Alzheimer's disease: in vivo relationship to cognitive deficit. Neurobiol Aging 1981;2:57-60.

${ }^{33}$ Marsden $\mathrm{CD}$. The enigma of the basal ganglia and movement. TINS November 1980.

${ }^{34}$ Mathews CG. Haaland KY. The effect of symptom duration on cognitive and motor performance in parkin- sonism. Neurology (Minneap), 1979;29:951-6.

${ }^{35}$ Stein L, Belluzi J, Wise CD. Memory enhancement by central administration of norepinephrine. Brain Res 1975;84:329-35.

${ }^{36}$ Shoulson I, Chase TN. Clonidine and the antiparkinsonian response to L-dopa or piribedil. Neuropharmacology 1976;15:25-7. 